\title{
MEGA-EMPREENDIMENTOS URBANOS E INJUSTIÇAS AMBIENTAIS: ALGUMAS REFLEXÕES A PROPÓSITO DO PROJETO NOVO RECIFE, RECIFE/PE
}

\author{
Sofia Barbosa Mahmood ${ }^{1}$ \\ Otávio Augusto Alves dos Santos ${ }^{2}$
}

\begin{abstract}
Resumo
Este trabalho procura debater o caráter socioambientalmente injusto de megaempreendimentos privados ligados ao mercado imobiliário, observando-se as especificidades da urbanização na cidade do Recife e as recentes nuances de sua dinâmica socioespacial, marcada pela consolidação do empreendedorismo como modelo de planejamento. Isso é feito a partir de uma análise crítica do Projeto Novo Recife, empreendimento imobiliário de luxo que ainda está em apreciação judicial, mas que tem proporcionado um amplo ambiente de debates na cidade em função de suas irregularidades e prováveis impactos socioambientais.
\end{abstract}

Palavras-chave: Justiça ambiental; Desigualdades socioambientais; Projeto Novo Recife.

\section{URBAN MEGA-PROJECTS AND ENVIRONMENTAL INJUSTICE: SOME REFLECTIONS ABOUT PROJETO NOVO RECIFE, RECIFE (BRAZIL)}

\begin{abstract}
The aim of this work is debate the socially and environmentally unjust character of private mega-projects related to the housing market, observing the specificities of urbanization in the city of Recife and the recent nuances of their socio-spatial dynamics, marked by the consolidation of entrepreneurship as a planning model. This is done from a critical analysis of the Projeto Novo Recife, luxury investment that is still in judicial review, but it has provided a broad discussion environment in the city because of its irregularities and probable social and environmental impacts.
\end{abstract}

Key-words: Environmental justice; Social-environmental inequalities; Projeto Novo Recife.

\section{MEGA-PROYECTOS URBANOS Y INJUSTICIA AMBIENTAL: REFLEXIONES SOBRE EL PROJETO NOVO RECIFE, RECIFE (BRASIL)}

\section{Resumen}

Este artículo trata de analizar el carácter socioambientalmente injusto de los mega-proyectos privados relacionados con el mercado de la vivienda, observando las características específicas de la urbanización en la ciudad de Recife y los últimos matices de su dinámica

\footnotetext{
${ }^{1}$ Graduada em Arquitetura e Urbanismo e Mestranda em Desenvolvimento Urbano pela Universidade Federal de Pernambuco (UFPE). Email: sofiabmahmood@gmail.com

${ }^{2}$ Graduado em Geografia, Mestre em Desenvolvimento Urbano e Doutorando em Desenvolvimento Urbano pela Universidade Federal de Pernambuco (UFPE). Email: otavioaas@gmail.com
}

Sociedade e Território - Natal. Vol. 28, N. 1, p. 122 - 136. Jan./Jun. de 2016 
socio-espacial, marcados por la consolidación de la actividad empresarial como un modelo de planificación. Esto se hace a partir de un análisis crítico del Projeto Novo recife, inversión de lujo que todavía se encuentra en la revisión judicial, pero se ha proporcionado un ambiente de amplia discusión en la ciudad debido a sus irregularidades e probables impactos socioambientales.

Palabras-clave: Justicia ambiental; Desigualdades sociambientales; Projeto Novo Recife.

\section{INTRODUÇÃO}

Como assegura Lefebvre (1999), o fenômeno da urbanização corresponde a um processo socioespacial que se originou a partir das cidades em função da industrialização capitalista, desenvolvendo-se para além delas junto ao próprio processo de reprodução ampliada do capital, constituindo a chamada sociedade urbana. Esse fenômeno inicia-se em Recife por volta do final do século XIX e, sobretudo, início do século XX, junto ao movimento histórico de modernização dessa cidade, intensificando um processo já existente de ocupação do solo marcado pela constituição de grandes desigualdades socioambientais.

Tomamos por desigualdade socioambiental, toda forma evidente de injustiça a um só tempo social e ambiental. No estudo das cidades isso requer que se leve em consideração o fato de que o espaço urbano é produzido de maneira diferenciada, de forma que a riqueza e os proveitos ambientais são desigualmente distribuídos. Há, com efeito, uma relação direta entre pobreza e proximidade espacial dos rejeitos produtivos, riscos e vulnerabilidades ambientais (ACSELRAD et al, 2009), da qual daremos destaque nessa interpretação da cidade do Recife e dos atuais desdobramentos da reprodução de seu espaço.

Acreditamos que tais desigualdades são ainda mais acirradas em função das atuais tendências do planejamento urbano que, como Harvey (2006) bem observou, tem procurado se inserir cada vez mais na lógica de acumulação do capital, adotando uma postura de empreendedorismo, onde os espaços das cidades têm sido estruturados com vistas a concorrência interurbana por ganhos econômicos. Essas transformações na governança das cidades têm feito com que os gestores urbanos se empenhem muito mais na concretização de planos locais de desenvolvimento voltado para atividades de serviços, sobretudo do turismo, relegando problemas de desigualdade social e ambiental urbanos para segundo plano.

Este trabalho procura debater o caráter socioambientalmente injusto de megaempreendimentos privados ligados ao mercado imobiliário, observando-se as especificidades da urbanização na cidade do Recife e as recentes nuances de sua dinâmica socioespacial, 
marcada pela consolidação do empreendedorismo como modelo de planejamento. Isso tem sido feito a partir de uma análise crítica do projeto Novo Recife, empreendimento imobiliário de luxo que ainda está em apreciação judicial, mas que tem proporcionado um amplo ambiente de debates na cidade em função de suas irregularidades e prováveis impactos. $\mathrm{Na}$ primeira parte deste trabalho, procuramos estabelecer as relações entre urbanização e injustiça ambiental no Recife, mostrando a forma socioambientalmente desigual que essa cidade tem se desenvolvido desde seu surgimento. Em seguida, tentamos resumir aspectos do Projeto Novo Recife, demonstrando seu caráter ambientalmente injusto. Por fim, buscamos apresentar o ideário da Justiça ambiental, ao mesmo tempo em que o estabelecemos enquanto possível parâmetro para processos de planejamento e gestão urbanos críticos.

\section{URBANIZAÇÃO E INJUSTIÇAS AMBIENTAIS NO RECIFE}

Recife se desenvolveu sobre um sítio físico-geográfico extremamente plano entrecortado por rios e alagados, e cercado por colinas, lembrando um anfiteatro. Castro (1948, p. 16) descreve a região como:

[...] uma planície constituída de ilhas, penínsulas, alagados, mangues e pauis, envolvidos pelos braços d'água dos rios que, rompendo passagem através da cinta sedimentar das colinas, se espraiam remansosos pela planície inundável. Foi nesses bancos de solo ainda mal consolidados - mistura ainda incerta de terra e de água que nasceu e cresceu a cidade do Recife, chamada de cidade anfíbia, como Amsterdã e Veneza, porque assenta as massas de sua construção quase dentro de água, aparecendo numa perspectiva aérea, com seus diferentes bairros flutuando esquecidos à flor das águas.

Sua formação, durante os dois últimos séculos, deu-se por um processo de ocupação desigual, onde as terras firmes e secas foram apropriadas por parte das classes mais abastadas, relegando aos pobres os alagados e encostas de morros, lugares que para serem devidamente ocupados requerem conhecimentos técnicos e a posse de equipamentos que tais populações não dispõem (FALCÃO NETO \& SOUZA, 1985; SANTOS, 2013). Desde os primeiros séculos, na parte central da cidade, o contraste entre as habitações das populações já era visível: os altos sobrados das famílias mais abastadas ocupavam as terras firmes e mais valorizadas, contrapondo com os mocambos ${ }^{3}$, habitações precárias onde viviam "as gentes de costelas à mostra", a população mais pobre e injustiçada (CASTRO, 1968; FALCÃO NETO \& SOUZA, 1985).

\footnotetext{
${ }^{3}$ Mocambo era uma forma de moradia vernácula geralmente localizada em áreas non aedificandi ou desocupadas.
}

Sociedade e Território - Natal. Vol. 28, N. 1, p. 122 - 136. Jan./Jun. de 2016 
No final do século XIX, a cidade já apresentava um cenário de forte desigualdade social, pois havia se constituído sob forte densidade populacional em função das diversas explosões demográficas. A abolição da escravatura, a concentração de terras no campo e a industrialização foram responsáveis por levar um enorme contingente de pessoas para o Recife entre as décadas de 1890 e 1930, acarretando no aumento significativo dos mocambos na cidade. Segundo o recenseamento realizado para a cidade na década de 1930, foi constatada a existência de 45.581 mocambos, o que correspondia a 67\% das habitações do Recife, estando grande parte deles localizados nos alagados próximo ao centro (BEZERRA, 1965; FALCÃO NETO \& SOUZA, 1985).

Dessa forma foi que a cidade do Recife se expandiu e, depois se adensou no início do século XX. A demanda crescente pelas terras enxutas fez com que as mesmas se tornassem cada vez mais valorizadas e inacessíveis. Contudo, logo surgiu o interesse, por parte das classes mais abastadas, pelas terras alagadas para a prática do aterro, o que possibilitava sua ocupação e uso econômico. Muitos mocambeiros foram retirados de suas casas para apropriação desses espaços por parte da população mais rica, que conseguiam tal direito por meio do instituto do "aforamento". A população pobre desprovida de recursos materiais viase cada vez mais distante da possibilidade de garantir um "pedaço de chão", sendo empurrada para terrenos cada vez mais distantes e ambientalmente degradados, lugares muitas vezes propícios a alagamentos ou deslizamentos de terra, onde estavam vulneráveis aos riscos de acidentes ambientais e doenças (BEZERRA, 1965; FALCÃO NETO \& SOUZA, 1985; SOUZA, 2002). Constituía-se no Recife, dessa forma, os primeiros quadros de desigualdade socioambiental.

O processo histórico de modernização e, consequentemente, de urbanização desta cidade, iniciado nas primeiras décadas do século XX, intensificou ainda mais essas desigualdades. O desejo do controle e higienização, bem como de reformulação espacial da cidade incitaram o aparecimento de planos e projetos marcados pela abertura de vias, bem como pelo incentivo a um padrão construtivo verticalizado. Os programas que se destinavam ao provimento de habitação, por sua vez, pautavam-se na lógica da realocação de famílias para conjuntos habitacionais distantes do centro, de forma que a acesso a cidade foi se tornando um privilégio de poucos, fazendo com que os mais pobres tivessem que viver nos lugares mais distantes, sem acesso a serviços básicos, como saneamento, educação e saúde. O Recife apresenta hoje um dos piores índices de Gini $(0,68)$ entre as cidades brasileiras 
(PNUD, 2010), embora possua o quinto metro quadrado $\left(5^{\circ} \mathrm{m}^{2}\right)$ mais caro do Brasil (YAZBEK, 2015). Segundo estimativas da Empresa de Limpeza Urbana do Recife (Emlurb), dos $54 \mathrm{~km}^{2}$ de áreas planas da cidade, $37 \mathrm{~km}^{2}$ estão sujeitas a alagamentos. O Recife ainda possui cerca de 3.400 pontos de risco de desabamento em morros e, segundo estimativas da Companhia Pernambucana de Saneamento (Compesa), apenas 35\% do território municipal é efetivamente saneado ${ }^{4}$.

A Lei de Uso e Ocupação do Solo da Cidade do Recife (Lei n ${ }^{\circ}$ 14.511/83), bem como suas Zonas Especiais de Interesse Social (ZEIS), foram instituídas no sentido de reverter esse quadro. A intenção era que, mais tarde, com o Programa de Regularização das Zonas Especiais e Interesse Social (PREZEIS), houvesse um reconhecimento das áreas populares centrais na legislação urbanística e posterior melhoria urbana, fazendo com que os mais pobres pudessem ter igual acesso à cidade (SOUZA, 2007). Porém, a permanência do modelo de urbanização pautado na iniciativa privada e no mercado imobiliário, bem como a negligência do planejamento urbano em relação às questões sociais, fez com que as desigualdades socioambientais permanecessem, tornando-se uma das principais marcas da cidade. Assim, a despeito do que essa legislação intentava, os mais ricos ainda tendem a escapar dos riscos ambientais com mais facilidade, residindo em áreas mais protegidas e centrais, cujo solo tem maior valor, enquanto os mais pobres são empurrados para áreas vulneráveis, em ambientes mais degradados e sem infraestrutura básica

Nos últimos dez anos, contudo, o surgimento de mega-empreendimentos imobiliários, muito dos quais voltados para o turismo ou para o consumo de luxo tem tornado a discussão sobre as desigualdades socioambientais ainda mais atual. É o caso do Shopping Riomar, do complexo viário Via Mangue ${ }^{5}$, do Condomínio Le Parc e da Reserva do Paiva. Ambos foram construídos em ambientes vulneráveis e por meio de despejos, à revelia das especificidades sociais e ambientais locais. Em quase todos os casos, concomitante à consolidação de tais empreendimentos, constituem-se conflitos socioambientais de diversas escalas e intensidades.

\footnotetext{
${ }^{4}$ Informações sobre os problemas de infraestrutura no Recife foram extraídas de matéria especial do portal ne10.com, disponível em: http://especiais.ne10.uol.com.br/agenda_recife/index.html. Acesso em: 24/11/2014.

5 Via expressa para carros localizada entre os bairros de Boa Viagem e Pina, cuja extensão é de aproximadamente $4,5 \mathrm{~km}$ e cuja construção se deu por uma conflituosa ocupação do entorno de uma importante Área de Proteção Ambiental da cidade, o Parque dos Manguezais.
} 


\section{O PROJETO NOVO RECIFE E SEU CARÁTER SOCIOAMBIENTALMENTE INJUSTO}

É na esteira do processo de consolidação do empreendedorismo enquanto modelo de governança urbana que surge, na cidade do Recife, o mega-empreendimento "Projeto Novo Recife". Trata-se de um projeto imobiliário de caráter particular, proposto por um consórcio entre quatro empresas do ramo: Moura Dubeux, Queiroz Galvão, Ara Empreendimentos e GL Empreendimentos. O projeto está prestes a ser implementado numa das áreas mais valorizadas da cidade, no antigo Cais José Estelita, localizado entre o bairro do Cabanga e o Forte das Cinco Pontas (Figura 01). O local e seu entorno possuem uma arquitetura antiga, com muitos sobrados e edifícios de pequeno porte, casarios antigos e vários bens tombados, como a Igreja de São José e o próprio Forte das Cinco Pontas.

Figura 01: Espaço onde poderá ser construído os empreendimento Projeto Novo Recife.

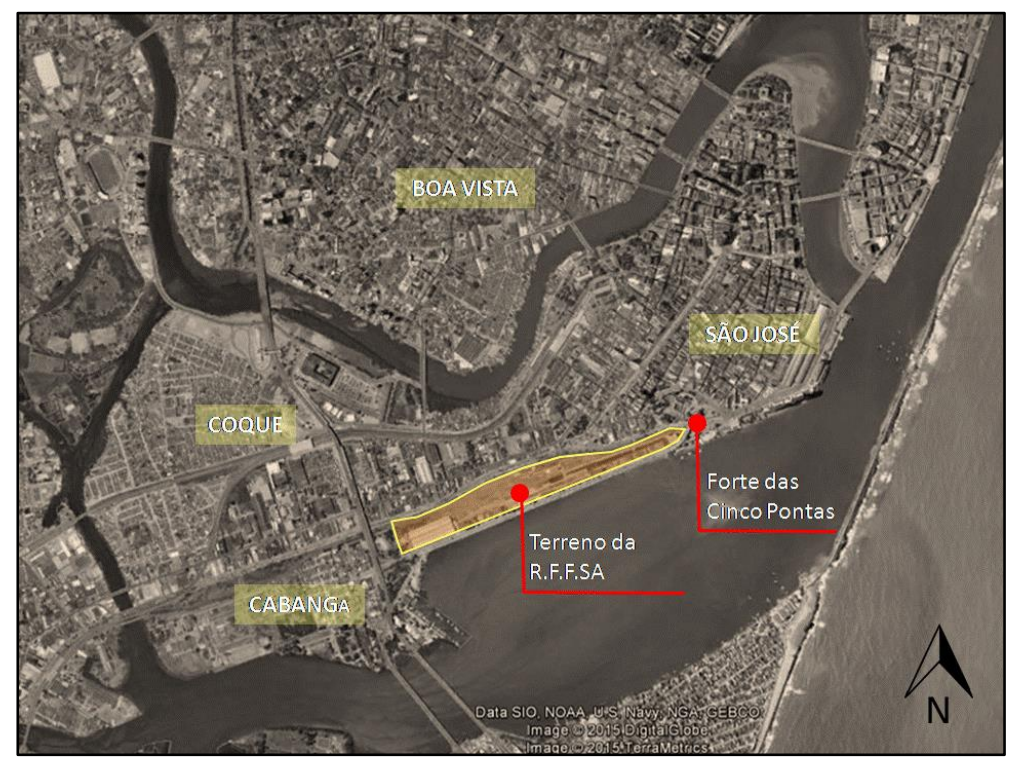

Fonte: Google Earth; Elaboração: Otávio Santos, 2015.

A área destinada ao projeto possui cerca de $101.000 \mathrm{~m}^{2}$ e está situada às margens da Bacia do Pina. O terreno, antes pertencente à Rede Ferroviária Federal SA. (RFFSA), patrimônio da união, foi adquirido pelo consórcio por meio de leilão comprovadamente ilegal. Tendo a proposta de revitalização, as empresas propõem inicialmente a construção de treze (13) edifícios, que variam entre vinte (20) e quarenta (40) pavimentos, destinados ao funcionamento de redes hoteleiras, escritórios e habitação de alto padrão, estando apenas $45 \%$ 
da área do terreno destinados aos espaços públicos, como praças, ciclovias e espaços culturais (Figura 02).

Figura 02: Imagem virtual do Projeto Novo Recife.

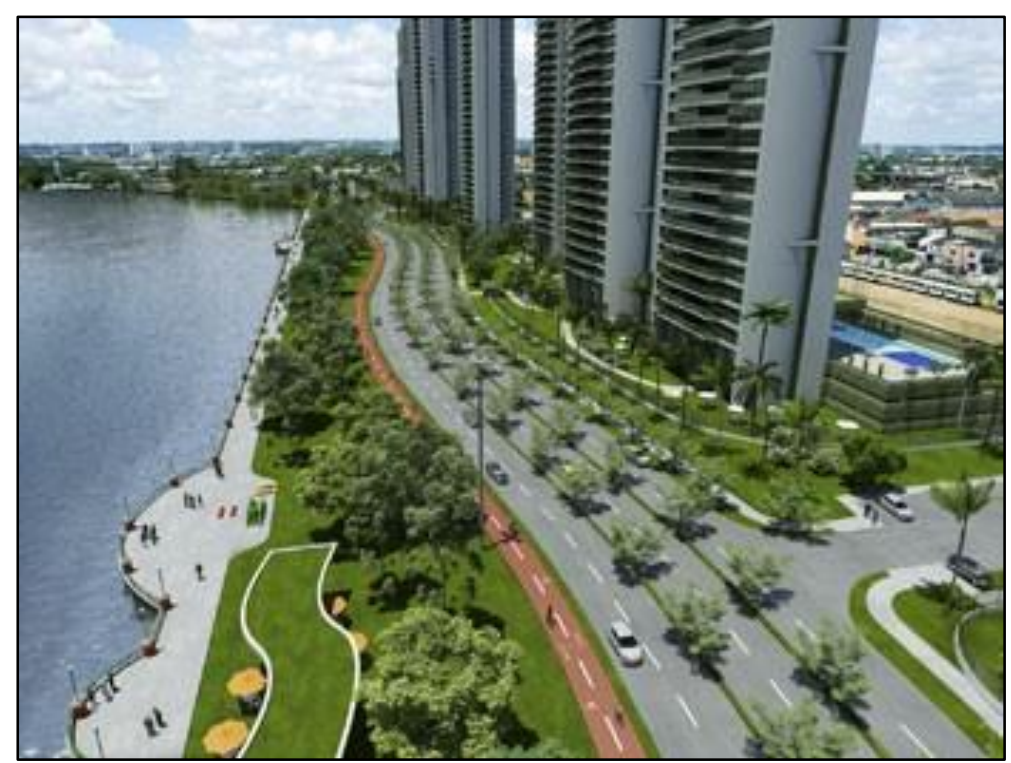

Fonte: G1.globo.com; Disponível em: http://g1.globo.com/pernambuco/noticia/2013/12/projeto-novo-recife-eaprovado-com-valor-dobrado-de-mitigacoes.html; Acesso em: 07/09/2014.

Cabe registrar que o Projeto Novo Recife surgiu, em grande parte, em função do abandono, por parte do poder público, de outro projeto que visava revitalizar inúmeras localidades da Região Metropolitana do Recife, o projeto "Complexo turístico-cultural Recife/Olinda", de 2006. Este projeto, por sua vez, correspondia a uma versão aparentemente mais democrática do "Projeto Capital"", de 1999, e do Plano Metrópoles, de 2001. Para a formulação destes últimos, foram chamados diversos intelectuais e técnicos locais, além de urbanistas internacionais, muitos dos quais inspirados no modelo de planejamento urbano levado a termo no processo de remodelação de algumas áreas da cidade de Barcelona em função dos jogos olímpicos de 1992. Tanto o Plano Metrópoles como o Complexo Recife/Olinda apontavam a área do Caís José Estelita (Figura 03) como "território de

\footnotetext{
${ }^{6}$ O Projeto Capital reunia um conjunto de estratégias para o setor imobiliário, entre elas uma série de operações para os bairros centrais, sua elaboração se deu a partir de diversos seminários, com a presença de intelectuais e técnicos locais, além de urbanistas estrangeiros. Na ocasião, também foi criado o "Fórum Capital", responsável pelos debates e estudos a respeitos dos planos de intervenção. O referido projeto não chegou a ser efetivamente implantado, mas um dos seus territórios de intervenção foi objeto de lei para posterior construção de plano urbanístico, a Área Temporária de Reurbanização do Cais José Estelita, criada pela Lei municipal $\mathrm{n}^{\circ}$ $16.550 / 2000$ (NUNES, 2013).
} 
oportunidades" econômicas. O fim do projeto Complexo Recife/Olinda fez com que a área ficasse disponível para as investidas do capital imobiliário.

Figura 03: Imagem aérea do Cais José Estelita.

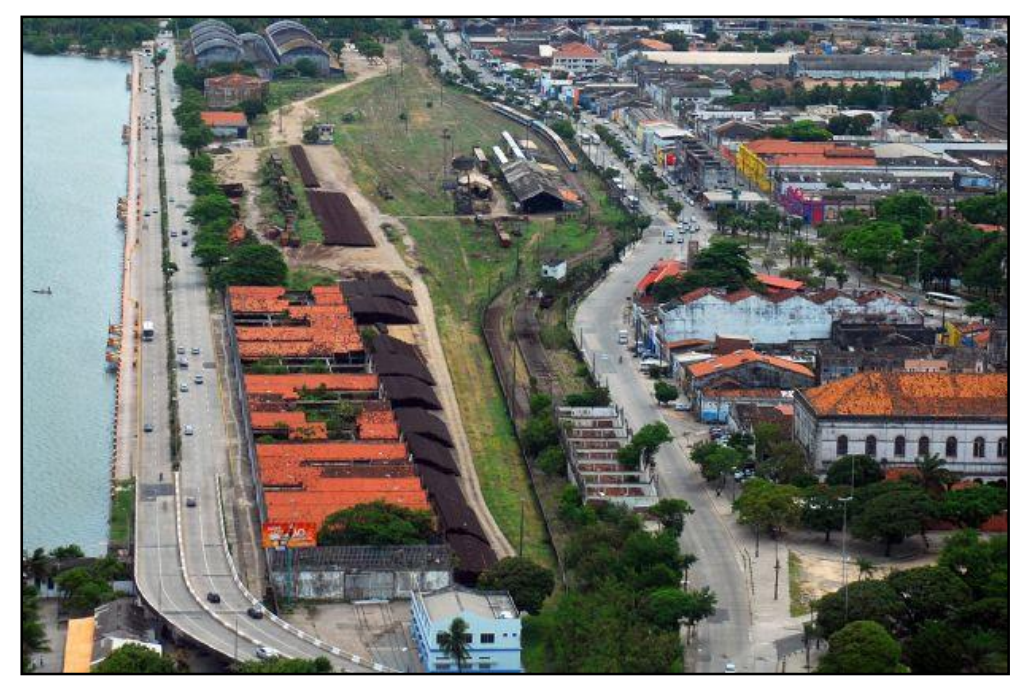

Fonte: Blenda Souto Maior/DP; Disponível em:

http://www.old.diariodepernambuco.com.br/nota.asp?Materia=20120408131426; Acesso em: 10/01/2015.

O caráter privatista e segregador do projeto Novo Recife gerou polêmicas e manifestações públicas por parte da população, levando estudantes, professores universitários, jornalistas, artistas e muitos trabalhadores a questionar a validade do projeto no que concerne a seus eventuais benefícios e impactos socioambientais. Foi, inclusive, nesse contexto de questionamento que insurgiu o grupo Direitos Urbanos, fórum de debates aberto e não institucionalizado sobre a cidade para onde convergiram as vozes contrárias ao projeto. Membros desse grupo, junto ao Ministério Público e outras entidades sociais foram os responsáveis em desencadear o debate público sobre o projeto, movendo ações judiciais que questionam alguns de seus aspectos, desde o repasse do terreno por parte da união até a ausência de estudos obrigatórios para a viabilização do empreendimento (Figura 04). 
Figura 4: Manifestação popular contra o Projeto Novo Recife.

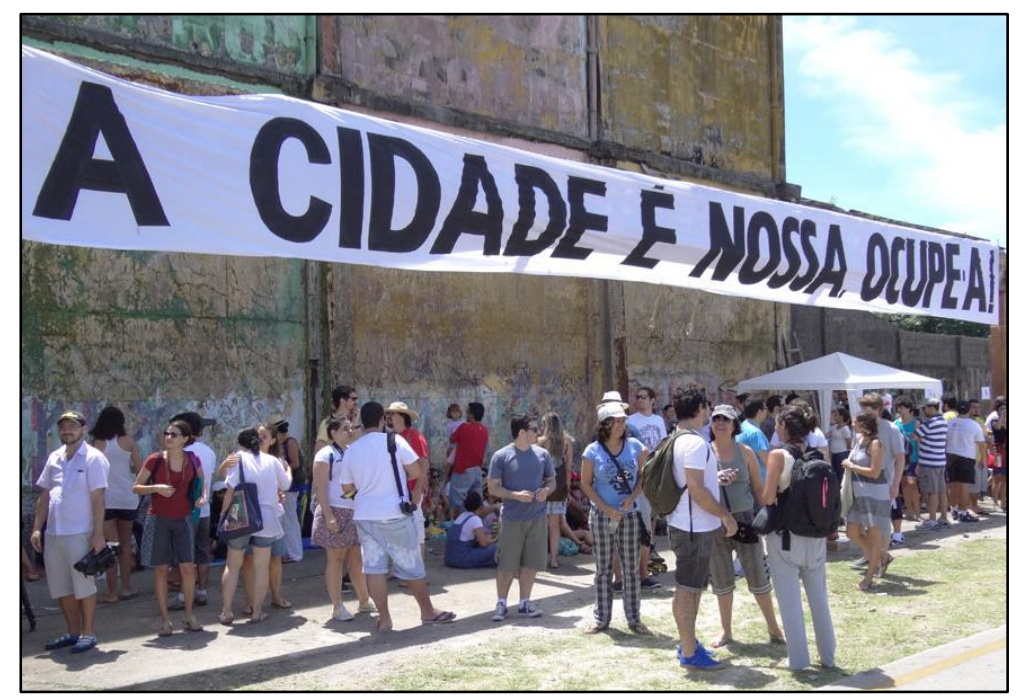

Fonte: Luna Markman/G1, 2012; Disponível em: http://g1.globo.com/pernambuco/fotos/2012/04/veja-fotos-domovimento-ocupe-estelita-no-recife.html; Acesso em: 07/09/2014.

Setores da sociedade passaram a reivindicar um planejamento urbano socioambientalmente justo, capaz de proporcionar à todos o direito àquele lugar, respeitando também a memória e o patrimônio histórico e cultural do Recife. Essa pressão popular forçou o poder público a realizar alguns ajustes no projeto, como a ampliação das ações mitigadoras e valorização dos espaços públicos. Neste sentido, foram incluídos à proposta um parque, além de equipamentos públicos como quadras poliesportivas, áreas de lazer, biblioteca pública, demolição do viaduto sobre o Forte das Cinco Pontas e implantação de ciclovias.

Contudo, os impactos socioambientais negativos superam e muito as ações mitigadoras ou quaisquer benefícios decorrentes da implantação do projeto, pois além de conservar o caráter privatista e segregador, o estilo arquitetônico dos edifícios previstos no projeto destoam enormemente daquele predominante nos bairros históricos circunvizinhos. Os aspectos negativos, então divulgados por diversos grupos sociais na sua luta contra o projeto, estão sendo objetos de pesquisas e estudos mais aprofundados. $\mathrm{O}$ frescor da mobilização contra o projeto faz com que ainda não se disponha de estudos mais detalhados sobre seus reais impactos, exceto algumas teses e dissertações defendidas, sobretudo, no Programa de Pós-graduação em Desenvolvimento Urbano da Universidade Federal de Pernambuco. Como os estudos obrigatórios de impacto ambiental e de vizinhança não foram realizados da maneira devida, ainda há poucos dados científicos que possam subsidiar os argumentos contra o Novo Recife. Entretanto, há evidências históricas e empíricas, há relatos de pessoas e 
comunidades inteiras que estão sendo impactadas. Há também um esforço científico recente para suprir essa necessidade de dados, conduzidos por estudantes, e grupos de pesquisas ligados à Universidade ${ }^{7}$. Neste sentido, pode-se resumir os impactos socioambientais negativos do projeto nos seguintes itens:

i) Possível fator de segregação residencial e gentrificação: $O$ projeto prevê a revitalização de uma importante área da cidade, propondo a construção de um espaço que em tudo destoa de seu entorno, tendo em vista que o terreno se situa entre bairros históricos e centrais da cidade, próximo também do Coque, bairro popular que possui uma história representativa de luta e permanência naquela região. Do ponto de vista socioespacial, a área revitalizada pelo projeto provavelmente não se integrará ao entorno, segregando-se enquanto um espaço de exclusividades para uma parcela específica da população. Ademais, a construção das treze torres, por certo, ocasionará na valorização econômica da área, no consequente aumento do custo de vida e na chamada gentrificação ou "expulsão branca" de moradores dos bairros de São José, do Coque e do Cabanga.

ii) Descaracterização do patrimônio arquitetônico da região: As modernas torres com mais de trinta pavimentos provavelmente bloquearão a vista (postal) que ainda se pode obter a partir da costa oceânica do sítio arquitetônico dos bairros de São José e Santo Antônio (VERAS, 2014). Os edifícios também ofuscarão a própria vista dos demais bairros centrais da cidade, como Boa Vista e Santo Amaro, discordando de seu estilo arquitetônico. Isso ocasionará impactos irreversíveis ao patrimônio histórico-cultural e arquitetônico da região ${ }^{8}$. O próprio bairro do Recife, lugar que tem sido gradualmente preservado e com edifícios e igrejas centenários, de valor histórico incomensurável, pode ser impactado.

iii) Impactos físico-ambientais nos ecossistemas locais: O projeto será construído na linha de costa, muito próximo da área estuarina da Bacia do Pina. O ambiente é vulnerável, mas proporcionalmente importante para a fauna e flora local, sendo berço de inúmeras espécies animais. A presença do empreendimento poderá desencadear uma sobrecarga desse ambiente no que concerne ao despejo de efluentes e poluição do ar, alterando não só o habitat de espécies animais e vegetais, mas também a vida de inúmeras famílias de pescadores e

\footnotetext{
${ }^{7}$ Para mais informações e dados a respeito de toda a luta contra o projeto, recomenda-se a visita à página eletrônica do grupo Direitos Urbanos: https://direitosurbanos.wordpress.com/

${ }^{8}$ Essa descaracterização do lugar, inclusive, tem sido um dos principais aspectos contra os quais se tem lutado, constituindo o mote por meio do qual grupos sociais como o Direitos Urbanos (como devido apoio do Ministério Público Federal e do Ministério da Cultura) tem impetrado junto aos institutos de memória o processo de tombamento do Pátio ferroviário das Cinco Pontas e de todo o Cais José Estelita.
} 
coletores de mariscos que garantem seu sustento na região. Além disso, as torres podem funcionar como barreira artificial para a brisa advinda do oceano, ocasionando o aumento da temperatura dos demais bairros localizados à oeste.

Por esses motivos, acredita-se que o Projeto Novo Recife tenderá à intensificação das desigualdades socioambientais da cidade, posto que não trará novidades no que concerne a forma através da qual a cidade tem sido produzida. Pelo contrário, o projeto poderá aumentar as injustiças ambientais da região, na medida em que visa criar um espaço exclusivo destinado a uma parcela específica da população, relegando à toda a cidade os impactos negativos de sua implantação e operação.

\section{JUSTIÇA AMBIENTAL: UM OBJETIVO PARA O PLANEJAMENTO URBANO CRÍTICO}

O surgimento de projetos urbanísticos impactantes como o Novo Recife tem chamado a atenção da opinião pública para a importância do planejamento urbano em cidades de mundo subdesenvolvido. Há uma cobrança por parte da população para que o Estado cumpra seu papel no que diz respeito a regulação do uso do solo, estabelecendo limites ao capital privado, protagonizando e viabilizando a participação social em grandes intervenções urbanísticas. A pressão popular, no caso do Recife, é ainda mais incisiva em função da postura de conivência dos governos em face das irregularidades e dos prováveis impactos negativos do projeto Novo Recife. Tem-se discutido, portanto, a importância de um planejamento urbano efetivo que opere com novos conceitos e que não se paute apenas no progresso econômico, mas acima de tudo no bem-estar socioambiental.

A propósito, foi com base nessa pressão popular que surgiu o Movimento Ocupe Estelita, coletivo aberto de estudantes, professores universitários e trabalhadores que passaram a ocupar o antigo terreno da RFFSA na perspectiva de desencadear um processo de luta e resistência popular contra o projeto Novo Recife (Figura 5). Tal movimento adquiriu grande notoriedade ao atrair inúmeros artistas locais que aderiram à causa, sendo também um dos assuntos mais discutidos nas redes sociais. 
Figura 5: Acampamento do Movimento Ocupe Estelita.

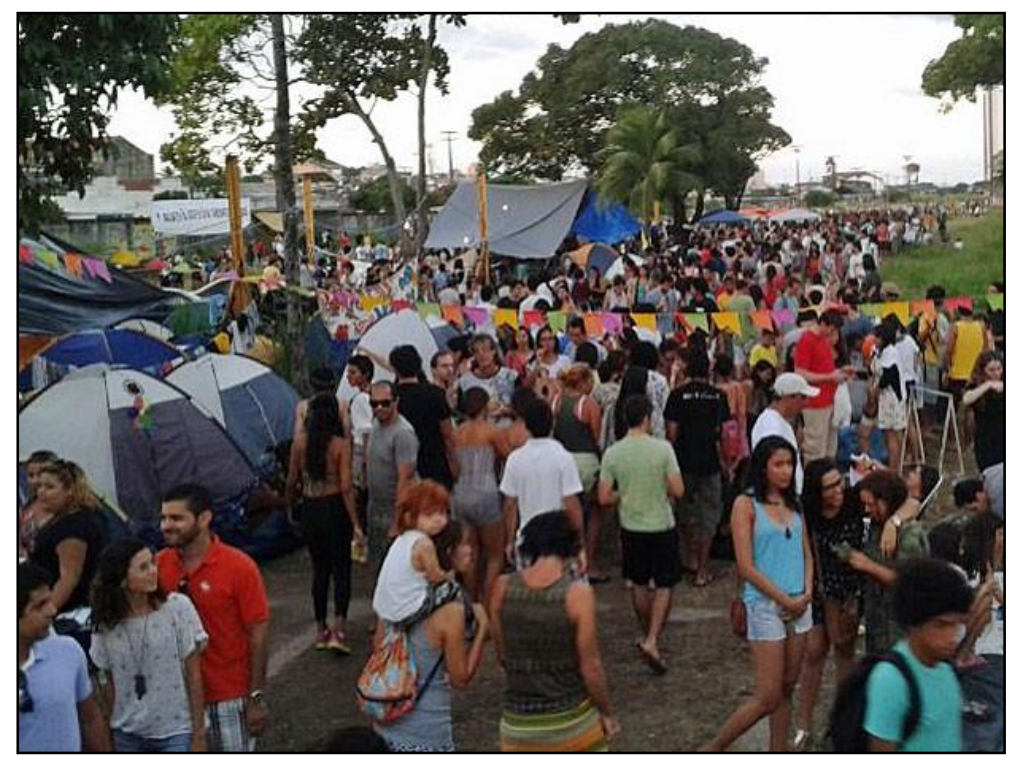

Fonte: Vítor Tavares/G1; Disponível em: http://g1.globo.com/pernambuco/noticia/2014/06/consorcio-novorecife-concorda-em-redesenhar-projeto-para-area-do-cais.html; Acesso em: 11/01/2015.

Vale dizer que o caráter conservador dos planos e projetos construídos para a cidade até então reafirmaram a leitura já difundida segundo a qual o planejamento urbano tem servido, antes de tudo, à manutenção do socioambientalmente injusto modelo de urbanização em voga. Contudo, como pondera Souza (2010), essas questões apenas reiteram a necessidade de se construir uma postura crítica a propósito do planejamento urbano, identificando seus defeitos, mas também reafirmando seu papel na promoção de uma cidade mais justa e democrática.

Neste sentido, Santos (2013), com base em Souza (2010), argumenta que mesmo imersos numa sociedade injusta, onde a prática do planejamento urbano tende a manter o status quo, ainda assim é possível vislumbrarmos um planejamento urbano crítico, desde que mantenhamos consolidados os compromissos com a construção da justiça ambiental. Isso significa reconhecer que no sistema político-econômico hegemônico há fissuras, de onde se podem obter ganhos sociais e ambientais importantes no curto prazo, além de uma mudança de mentalidade e cultura política no longo prazo.

Santos (2013) então defende um planejamento urbano crítico voltado a concretização da justiça ambiental. Para tanto, o autor considera necessário: i) romper com o modelo desigual de urbanização capitalista, quebrando a forte relação hoje existente entre as práticas de planejamento urbano e os interesses privados de acumulação do capital; ii) promover a 
cooperação intergovernamental entre municípios, sobretudo em regiões metropolitanas, uma vez que os problemas socioambientais urbanos quase nunca estão circunscritos em limites municipais; iii) construir mecanismo à plena participação social e; iv) implementar ações concretas de redução das desigualdades sociais e recuperação de ambientes urbanos degradados.

A justiça ambiental ao qual nos referimos corresponde aquela surgida no âmbito do Movimento por Justiça Ambiental (MJA), nos Estados Unidos, na década de 1980. O referido movimento, por seu turno, desenvolveu-se no seio do movimento negro estadunidense, a partir de questionamentos em torno da realidade urbana norte-americana, que relegava aos negros e demais grupos sociais excluídos os lugares mais degradados da cidade, bem como toda poluição gerada pelas atividades produtivas. Um dos principais articuladores desse movimento, o sociólogo Robert Bullard, sempre procurou demonstrar a relação direta existente entre os locais de moradia das pessoas negras com os depósitos de lixos tóxicos. Desde então, inúmeros trabalhos e ações sociais tem sido realizados, sob o fito de demonstrar a relação existente entre exclusão social e degradação ambiental, buscando combater as injustiças ambientais por meio da luta social organizada.

No Brasil, o conceito tem sido concebido enquanto mecanismo por meio do qual buscar-se reverter as situações de injustiça ambiental, construindo um "ambiente sadio e produtivo para todos", respeitando a autonomia e a dignidade de indivíduos e comunidades (ACSELRAD et al, 2009). Trata-se, assim, de um conceito útil no sentido de guiar as ações no âmbito do planejamento. Em Recife e, especificamente, no caso do Projeto Novo Recife, a justiça ambiental deve ser observada, servindo de mote para ação dos grupos sociais que lutam contra a concretização do projeto Novo Recife e dos formuladores dos planos, projetos e políticas públicas para a cidade.

\section{CONSIDERAÇÕES FINAIS}

Todos os debates desencadeados em função da aprovação e implementação do projeto Novo Recife surgiram por conta dos seus impactos evidentes, embora o consórcio esteja em uma verdadeira guerrilha midiática contra o grupo Direitos Urbanos, o Movimento Ocupe Estelita e contra todos aqueles que são contra o projeto. As empresas envolvidas possuem interesses comuns e compõem grupos empresarias que atuam em diversos ramos, inclusive o da comunicação. Por isso os canais de TV e rádio, assim como os principais jornais da região 
têm se empenhado na divulgação do que consideram benefícios do projeto, tais como geração de emprego e renda. Ainda assim, a maior parte da população, inclusive as comunidades localizadas no entorno do antigo terreno da RFFSA, mantém uma postura crítica e tem também se posicionado contra o projeto.

Mas a força de tais empresas provém, sobretudo, com o Estado, uma vez que a atual administração pública tem sido complacente com as irregularidades do projeto e tem se esforçado em deslegitimar toda força política que tem erigido contra os interesses do consórcio. Cabe registrar que as empresas envolvidas foram umas das principais financiadoras as campanhas eleitorais do atual prefeito e do governador do Estado, bem como de muitos vereadores e deputados estaduais. Isso tudo nos leva crer que o Novo Recife é muito mais que um simples projeto urbanístico, mas uma coalizão de interesses escusos, que envolve o Capital e o Estado, e que tem por principal objetivo a transformação da cidade em uma vitrine para o consumo de luxo e para o turismo, a revelia de suas desigualdades e das reais necessidades da população.

O projeto Novo Recife, portanto, pode levar a intensificação das desigualdades socioambientais da cidade, uma vez que não destoa da forma por meio da qual a cidade do Recife foi constituída - isto é, com base na constituição de desigualdades socioambientais. Pior, o projeto produzirá mais injustiças, intensificará as já existentes e, por fim, contribuirá para a consolidação do empreendedorismo como modelo de planejamento urbano. É neste sentido que a luta da população contra o projeto torna-se justa, devendo ser apoiada por todos aqueles que desejam um dia viver em cidades mais justas e democráticas. É neste sentido também que o ideário da justiça ambiental se avulta como necessário ordenador das práticas de planejamento e gestão da cidade, pois afirma que ninguém deve arcar desproporcionalmente com o desenvolvimento e que todos têm direito a viver bem, em um lugar sadio e livre de injustiças.

\section{REFERÊNCIAS}

ACSELRAD, H; MELLO, C. C. A; BEZERRA, G. N. O que é justiça ambiental? Rio de Janeiro: Garamond, 2009.

BEZERRA, D. U. C. Alagados, mocambos e mocambeiros. Recife: Fundaj/Imp. Universitária, 1965.

CASTRO, J. Fatores de localização da cidade do Recife: um ensaio de Geografia urbana. Rio de Janeiro: Imprensa Nacional, 1948.

Sociedade e Território - Natal. Vol. 28, N. 1, p. 122 - 136. Jan./Jun. de 2016 
CASTRO, J. Homens e caranguejos. 2 ed. São Paulo: Brasiliense, 1968

FALCÃO NETO, J. SOUZA, M. A. A. Mocambos do Recife: o direito de morar. Ciência Hoje, v. 3, n. 18, p. 74-80, 1985.

HARVEY, D. Do administrativismo ao empreendedorismo: a transformação da governança urbana no capitalismo tardio. In: HARVEY, D. A produção capitalista do espaço. 2.ed. São Paulo: Annablumme, 2006.

LEFEBVRE, H. De lo rural a lo urbano. 4.ed. Barcelona: Ediciones Península, 1978.

LEFEBVRE, H. A revolução urbana. Belo Horizonte: Ed. da UFMG, 1999

NUNES, S. M. M. Da teoria à prática: um breve histórico do planejamento urbano no Recife, pós 1970. In: XV Encontro da Associação Nacional de Pós-graduação e Pesquisa em Planejamento Urbano e Regional: desenvolvimento, planejamento e governança, 2013, Recife. Anais (on-line). Recife: UFPE, 2013. p. 01-16. Disponível: http://unuhospedagem.com.br/revista/rbeur/index.php/anais/article/view/4595/4464; Acesso em: 11 fevereiro 2015

PNUD, 2014. Atlas de Desenvolvimento Humano no Brasil. [online] Disponível na Internet via http://www.atlasbrasil.org.br/2013/pt/perfil_m/recife_pe; Acesso em: 15 fevereiro 2015

SANTOS, O. A. A. Planejamento urbano e problemas ambientais: redirecionamentos teórico-metodológicos ao enfrentamento da crise ambiental recifense. Geoambiente On-Line, v. 11, n. 21, p. 68-84, 2013.

SOUZA, M. A. A. O Recife das "Terras de Marinha". Revista do Instituto Arqueológico, Histórico e Geográfico Pernambucano. n. 59, p. 127-145, 2002.

Política habitacional para os excluídos: o caso da Região Metropolitana do Recife. In: CARDOSO, A. L. Habitação social nas cidades brasileiras: uma avaliação das políticas habitacionais em Belém, Belo Horizonte, Porto Alegre, Recife, Rio de Janeiro e São Paulo no final do século XX. Porto Alegre: Antac, 2007.

SOUZA, M. L. Mudar a cidade: uma introdução crítica ao planejamento e à gestão urbanos. 6.ed. Rio de Janeiro: Bertrand Brasil, 2010.

VERAS, L. M. S. C. Paisagem-postal: a imagem e a palavra na compreensão de um Recife urbano. 2014. 467 f. Tese (Doutorado) - Universidade Federal de Pernambuco / Programa de Pós-graduação em Desenvolvimento Urbano, Recife, 2014.

YAZBEK, P. Revista Exames: As cidades com imóveis mais caros e mais baratos de 2014. [online] Disponível na Internet via http://exame.abril.com.br/seu-dinheiro/noticias/as-cidadescom-imoveis-mais-caros-e-mais-baratos-de-2014/lista; Acesso em: 11 fevereiro 2015

Recebido em Janeiro de 2015

Aprovado em Fevereiro de 2016

Publicado em Junho de 2016

Sociedade e Território - Natal. Vol. 28, N. 1, p. 122 - 136. Jan./Jun. de 2016 